\title{
Photolysis of Diazo Dye in Solutions and Films Containing Zinc and Silver Oxides
}

\author{
O. V. Istomina ${ }^{a}$, S. K. Evstropiev ${ }^{b}, *$ E. V. Kolobkova ${ }^{a, b}$, and A. O. Trofimov ${ }^{b}$ \\ ${ }^{a}$ St. Petersburg State Technological Institute (Technological University), St. Petersburg, 190013 Russia \\ ${ }^{b}$ ITMO University, St. Petersburg, 197101 Russia \\ *e-mail: evstropiev@bk.ru
}

Received December 20, 2017; in final form, February 15, 2018

\begin{abstract}
Photolysis of Chicago Sky Blue diazo dye in aqueous solutions and films containing zinc and silver oxides is studied. The presence of zinc and silver nitrates in aqueous solutions of this dye considerably increase the rate of its photolysis under UV irradiation. $\mathrm{ZnO}$ and $\mathrm{ZnO}: \mathrm{Ag}$ oxide films and composite coatings with zinc and silver nitrates also considerably affect the photolysis of Chicago Sky Blue diazo dye.
\end{abstract}

DOI: $10.1134 / \mathrm{S} 0030400 X 18060097$

\section{INTRODUCTION}

The photocatalytic properties of various materials have been extensively studied in a number of works [1-5]. This is largely related to the development of new materials and films with a new combination of functional properties (optical, photocatalytic, and bactericide) [2-8]. In addition, upgrading of the methods of UV treatment of air and aqueous media, sterilization of solid surfaces, and removal of organic pollutants are urgent ecological problems [3, 7, 9-11].

At present, numerous studies are devoted to the development of photocatalytic and bactericide materials based on zinc oxides [1, 2, 4, 6, 8, 13-16]. The low cost and high photocatalytic properties of these materials make them promising for wide practical application. It was shown in $[2,6,13]$ that the functional characteristics of zinc oxides can be considerably improved by doping with oxides of other metals (Ag, Ce, Ti).

Diazo dyes are rather widely used in industry, and the development of methods of water purification from these dyes is an important problem [3, 12]. Solutions of the Chicago Sky Blue (CSB) diazo dye are used to determine the photocatalytic properties of various materials $[4,11,12,17,18]$. The spectral properties of this dye are well known [19], and the structure of its molecule is presented in [4]. In [4], we showed that the presence of metal nitrates in CSB solutions changes the mechanism of photolysis and sharply increases its rate.

The aim of the present work is to experimentally study the photocatalytic degradation of the diazo dye in solutions and coatings containing zinc and silver oxides.

\section{EXPERIMENTAL}

We studied aqueous solutions of zinc and silver nitrates, as well as aqueous solutions of CSB 6B organic dye (Sigma-Aldrich). Preliminarily weighed batches of powders were dissolved with stirring in distilled water. The solutions obtained were mixed with each other or with addition of water in required proportions.

Addition of macromolecular polyvinylpyrrolidone (PVP) $\left(M_{w}=1300000\right.$, Sigma-Aldrich) to the composition of film-forming solutions allows one to form homogeneous composite layers transparent in the visible spectral range on glass surfaces [20]. Therefore, in the present work, we added a solution of this polymer in propanol-2 to the film-forming solutions with the diazo dye. The coatings were deposited by immersing the glass samples into the film-forming solution, after which the samples were withdrawn and dried. The obtained composite films containing metal nitrates and PVP were highly homogeneous.

To form oxide films on glass surfaces, the samples with composite coatings were thermally treated in a laboratory furnace at a temperature of $550^{\circ} \mathrm{C}$ for $2 \mathrm{~h}$. This method ensures formation of transparent and homogeneous films consisting of oxide nanoparticles [21]. The thickness of the composite films was 300$600 \mathrm{~nm}$.

To estimate the photocatalytic properties of the oxide films obtained, their surface was coated with CSB/PVP composite films by immersion into an aqueous solution. The use of PVP-containing solutions ensured a homogeneous dye distribution over the sample surfaces. 

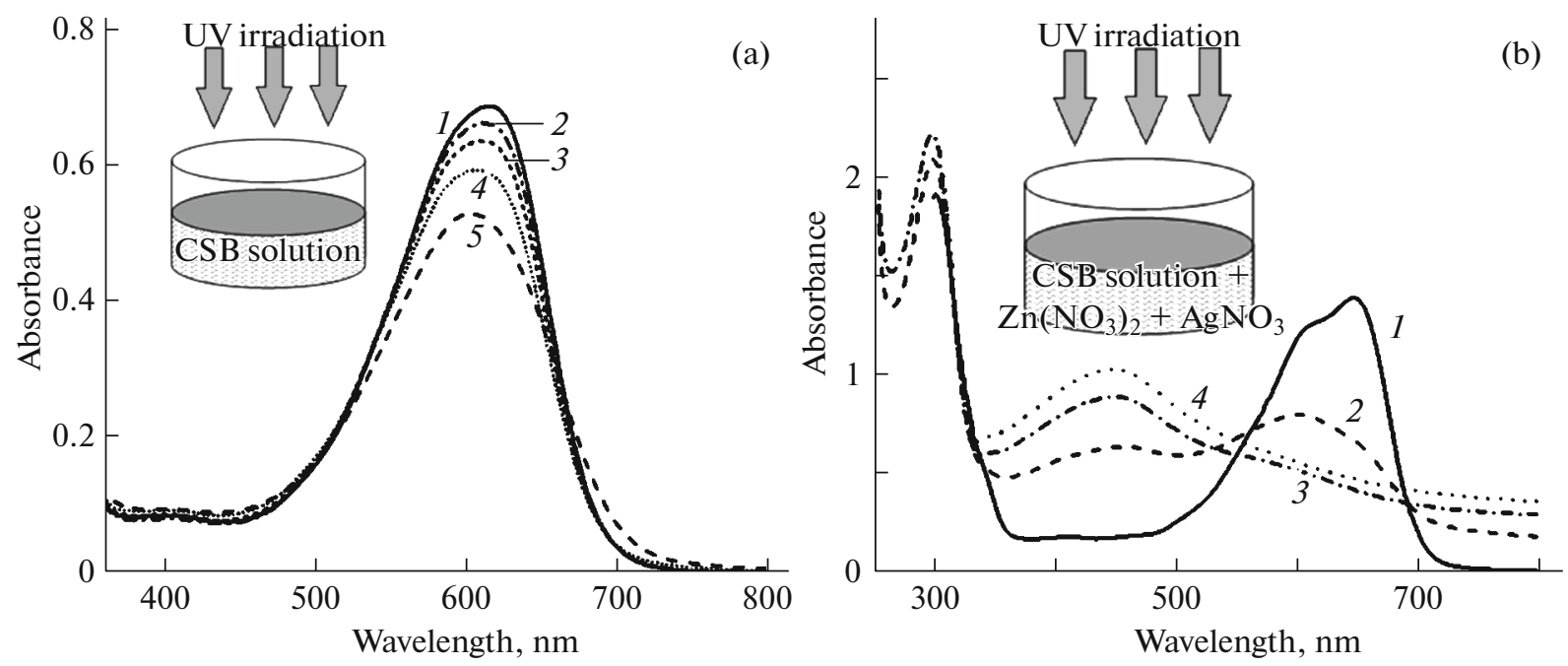

Fig. 1. Changes caused by UV radiation of a mercury lamp in the absorption spectra of aqueous solutions of (a) $\mathrm{CSB}\left(8.7 \times 10^{-6} \mathrm{M}\right)$ with PVP $\left(1.1 \times 10^{-5} \mathrm{M}\right)$ and (b) $\operatorname{CSB}\left(8.7 \times 10^{-6} \mathrm{M}\right)$ with PVP $\left(1.1 \times 10^{-5} \mathrm{M}\right), \mathrm{Zn}\left(\mathrm{NO}_{3}\right)_{2}(0.11 \mathrm{M})$, and $\mathrm{AgNO}_{3}(0.06 \mathrm{M})$. The curves correspond to (1) initial solutions and solutions irradiated for (2) 5, (3) 10, (4) 20, and (5) $30 \mathrm{~min}$.

The absorption spectra of solutions were recorded in quartz cells on a PerkinElmer Lambda 650 spectrophotometer. The solutions were irradiated by a DRT240 high-pressure mercury lamp. The spectrum of this lamp is presented in [22]. The radiation-power density was $0.25 \mathrm{~W} / \mathrm{cm}^{2}$.

The morphology and thickness of oxide films were studied by scanning electron microscopy on a TescanVega 3 SBH microscope. The thickness of oxide films was determined using electron-microscope images of film slices. The thickness of the oxide coatings was $150-200 \mathrm{~nm}$.

\section{EXPERIMENTAL RESULTS AND DISCUSSION}

Figure 1 illustrates changes in the absorption spectra caused by photodecomposition of CSB (Fig. 1a), as well as in aqueous solution with a mixture of zinc and silver nitrates. The spectra before irradiation exhibit an intense absorption band in the visible range with somewhat different shapes. This difference is explained both by a slight difference in the dye concentration and by the effect of metal cations in the solutions.

According to [9], intermolecular interaction and formation of dimers and trimers of dye molecules may occur in aqueous solution with CSB concentrations exceeding $10^{-7}-10^{-6}$. This complicates the structure of the absorption band, changes its intensity in the visible range, and causes the appearance of a bend or an additional maximum in the long-wavelength region (Fig. 1). Based on [4, 23], we may suggest that the presence of metal ions, which can form complexes with CSB molecules, is also responsible for the changes in the structure of this absorption band.
Comparison of the data obtained upon irradiation of different solutions allows us to conclude that the presence of zinc and silver nitrates in the solutions considerably accelerates photolysis of the dye and significantly changes the character of changes occurring in the absorption spectra of solutions.

The absorption spectra of solutions with nitrate additives clearly exhibit an absorption band in the UV region with a maximum at $\lambda_{\max } \sim 300 \mathrm{~nm}$. This band results from superposition of the absorption bands of $\mathrm{NO}_{3}^{-}$anions and the dye molecules. Ultraviolet irradiation of solutions causes dissociation of $\mathrm{NO}_{3}^{-}$anions $[9,24]$, which is accompanied by formation of chemically active products, which, in turn, may participate in decomposition of organic compounds [9]. It can be suggested that it is these processes with participation of $\mathrm{NO}_{3}^{-}$anions that determine the observed strong acceleration of the diazo dye photolysis in the presence of metal nitrates.

Under the action of UV irradiation, the color of the solutions rapidly changes. The CSB absorption-band intensity in the visible range decreases and the band maximum shifts to shorter wavelengths. Comparison of the changes observed under UV irradiation in the absorption spectra of the solutions with a mixture of zinc and silver nitrates (Fig. 1b) shows that introduction of silver nitrate in the solution exerts no noticeable effect on the photolysis rate. It is also seen that the spectra of irradiated solutions (Fig. 1a) in the presence of silver ions contain a typical plasmon absorption band of silver nanoparticles with $\lambda_{\max } \sim 450 \mathrm{~nm}$ [25]. It is likely that the presence of PVP, which plays the role 

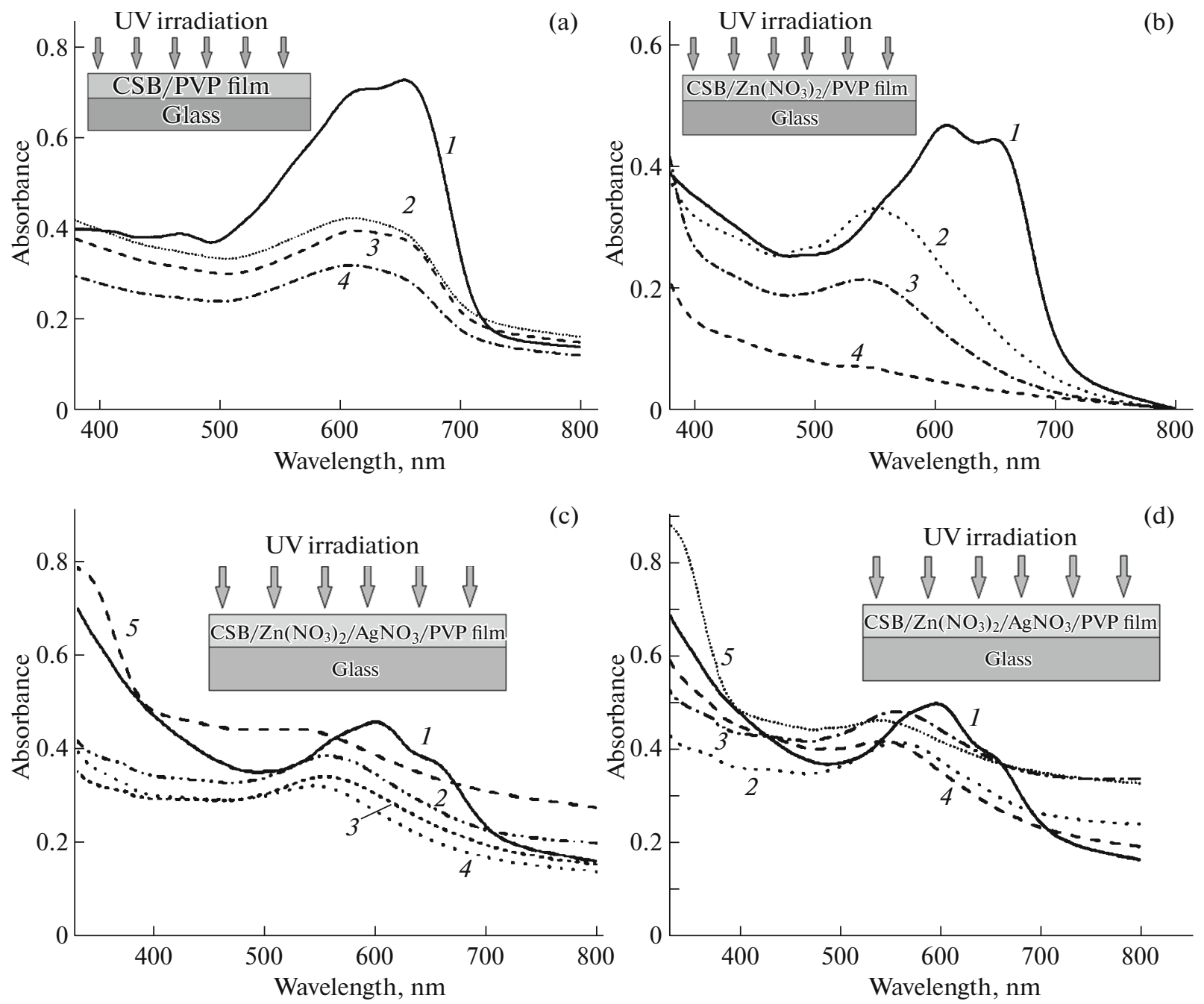

Fig. 2. Changes caused by UV radiation of a mercury lamp in the absorption spectra of glass samples with (a) CSB/PVP film (CSB 0.06 wt \%, PVP 99.94 wt \%), (b) PVP/Zn( $\left(\mathrm{NO}_{3}\right)_{2}$ composite film covered by a CSB/PVP layer $\left(\mathrm{CSB} 0.02 \mathrm{wt} \%, \mathrm{Zn}\left(\mathrm{NO}_{3}\right)_{2}\right.$ 59.39 wt \%, PVP 40.59 wt \%), (c) PVP $/ \mathrm{Zn}\left(\mathrm{NO}_{3}\right)_{2} / \mathrm{AgNO}_{3}$ film covered by a CSB/PVP layer $\left(\mathrm{CSB} 0.02 \mathrm{wt} \%, \mathrm{Zn}\left(\mathrm{NO}_{3}\right)_{2}\right.$ 57.75 wt \%, $\mathrm{AgNO}_{3} 2.76$ wt \%, PVP 39.47 wt \%), and (d) PVP/Zn( $\left(\mathrm{NO}_{3}\right)_{2} / \mathrm{AgNO}_{3}$ composite film covered by a CSB/PVP layer $\left(\mathrm{CSB} 0.02 \mathrm{wt} \%, \mathrm{Zn}\left(\mathrm{NO}_{3}\right)_{2} 56.07 \mathrm{wt} \%, \mathrm{AgNO}_{3} 5.59 \mathrm{wt} \%, \mathrm{PVP} 38.32 \mathrm{wt} \%\right)$. The curves correspond to (1) initial solutions and solutions irradiated for (2) 10 , (3) 20, (4) $30 \mathrm{~min}$.

of a surfactant in the solution, facilitates stabilization of these nanoparticles.

Figure 2 illustrates the changes in the absorption spectra due to photodissociation of the dye in CSB/PVP composite films deposited on a glass surface (Fig. 2a), as well on preliminarily deposited coatings $\mathrm{PVP} / \mathrm{Zn}\left(\mathrm{NO}_{3}\right)_{2}$ (Fig. 2b) and PVP/Zn( $\left(\mathrm{NO}_{3}\right)_{2} / \mathrm{AgNO}_{3}$ (Figs. 2c, 2d). The polymer-salt films preliminarily deposited on glass surfaces were homogeneous and transparent in the visible-spectral region (Fig. 2a, curve 1).

Coating of this film by a film with CSB leads to the appearance of the absorption band typical for this dye in the range of 600-700 $\mathrm{nm}$ (Fig. 2a, curve 2). Upon drying of the PVP/CSB film deposited from the solu- tion, the solvent evaporates and the dye concentration in the film becomes considerably higher than in the solution. This determines the observed shape of the absorption band, which is characterized by two closely spaced maxima. Irradiation of samples with this coating causes dye photolysis, the absorption-band intensity decreases (Fig. 2a), and the sample color noticeably bleaches and changes from blue to light blue.

Ultraviolet irradiation of the samples with the composite coating containing PVP and zinc nitrate considerably decreases the intensity of the diazo-dye absorption band and shifts its maximum to the blue (Fig. 2b). The dye photolysis leads to a strong change in the sample color from blue to pink. The difference observed in the absorption spectra of samples indicate 


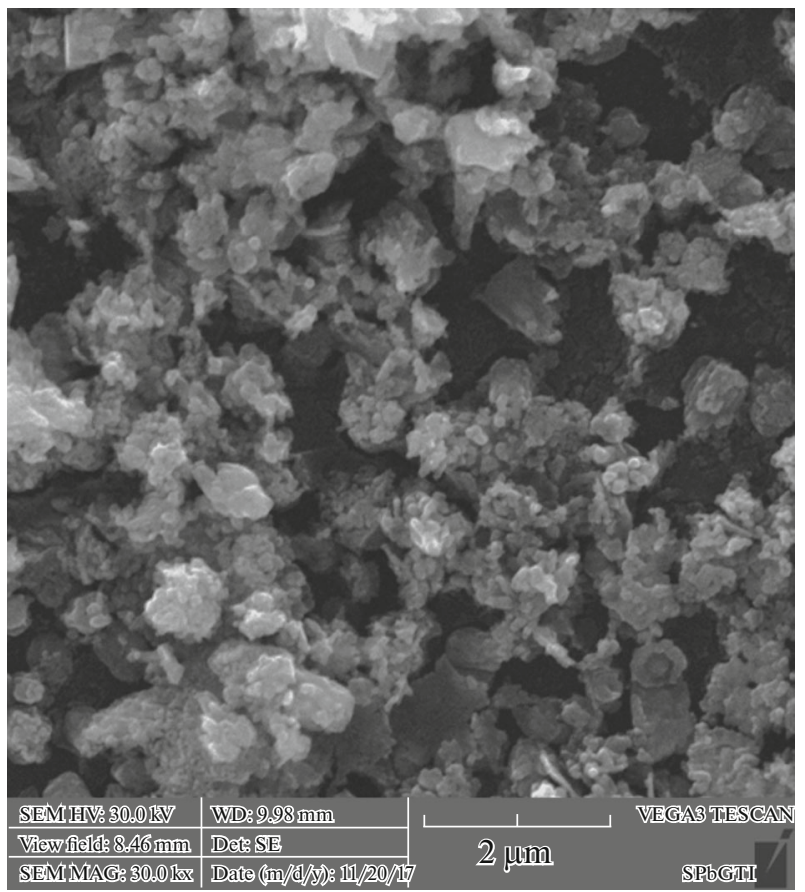

Fig. 3. Electron-microscope image of a $\mathrm{ZnO}: \mathrm{Ag}$ film on a glass surface. The film composition is $\mathrm{ZnO} 86.3 \mathrm{wt} \%$, $\mathrm{Ag}_{2} \mathrm{O} 13.7 \mathrm{wt} \%$.

that, despite the screening effect of the outer $\mathrm{CSB} / \mathrm{PVP}$ coating, UV radiation reaches the underlying polymer-salt film, and the photochemical processes in the latter considerably affect the dye photolysis in the outer coating.

Irradiation of samples with a $\mathrm{PVP} / \mathrm{Zn}\left(\mathrm{NO}_{3}\right)_{2} / \mathrm{AgNO}_{3}$ composite film coated by a CSB/PVP film by a mercury lamp leads to a consider- able change in their absorption spectra (Figs. 2c, 2d). The spectra of irradiated samples exhibit a decrease in the intensity of the dye absorption band and a shortwavelength shift of its maximum. As a result of UV irradiation, the shape of the spectra considerably changes due to a strong increase in the short-wavelength absorption. UV irradiation of samples with $\mathrm{PVP} / \mathrm{Zn}\left(\mathrm{NO}_{3}\right)_{2} / \mathrm{AgNO}_{3}$ coatings changes their color from blue to gray.

A change in the silver nitrate concentration in the $\mathrm{PVP} / \mathrm{Zn}\left(\mathrm{NO}_{3}\right)_{2} / \mathrm{AgNO}_{3}$ composite film almost has almost no effect on the character of the diazo-dye evolution upon photoirradiation (Figs. 2c, 2d). The absence of this influence can be explained by the relatively high concentrations of zinc and silver nitrates in the polymer-salt film. Figures $2 \mathrm{c}$ and $2 \mathrm{~d}$ show that the introduction of more than $2 \%$ of silver nitrate into the film composition causes no additional acceleration of the diazo-dye photolysis.

Figure 3 presents electron-microscope images of a $\mathrm{ZnO}: \mathrm{Ag}$ coating formed on a glass surface. It is seen that the film consists of submicron aggregates formed by particles about $100 \mathrm{~nm}$ in size. This structure of the coating ensures a large specific surface area of the material and the possibility of active interaction with environment.

The deposition of a thin CSB/PVP coating onto the surface of oxide films leads to the appearance of absorption bands typical for CSB (Fig. 4). UV irradiation causes rapid decomposition of the dye and a decrease in the absorption-band intensity in the visible region of the spectrum. At the same time, absorption in the blue region slightly increases, which is most pronounced in the films deposited on the surface of $\mathrm{ZnO}: \mathrm{Ag}$ coatings. Comparison of Figs. $4 \mathrm{a}$ and $4 \mathrm{~b}$ shows that the photolysis of the dye in films on the sur-
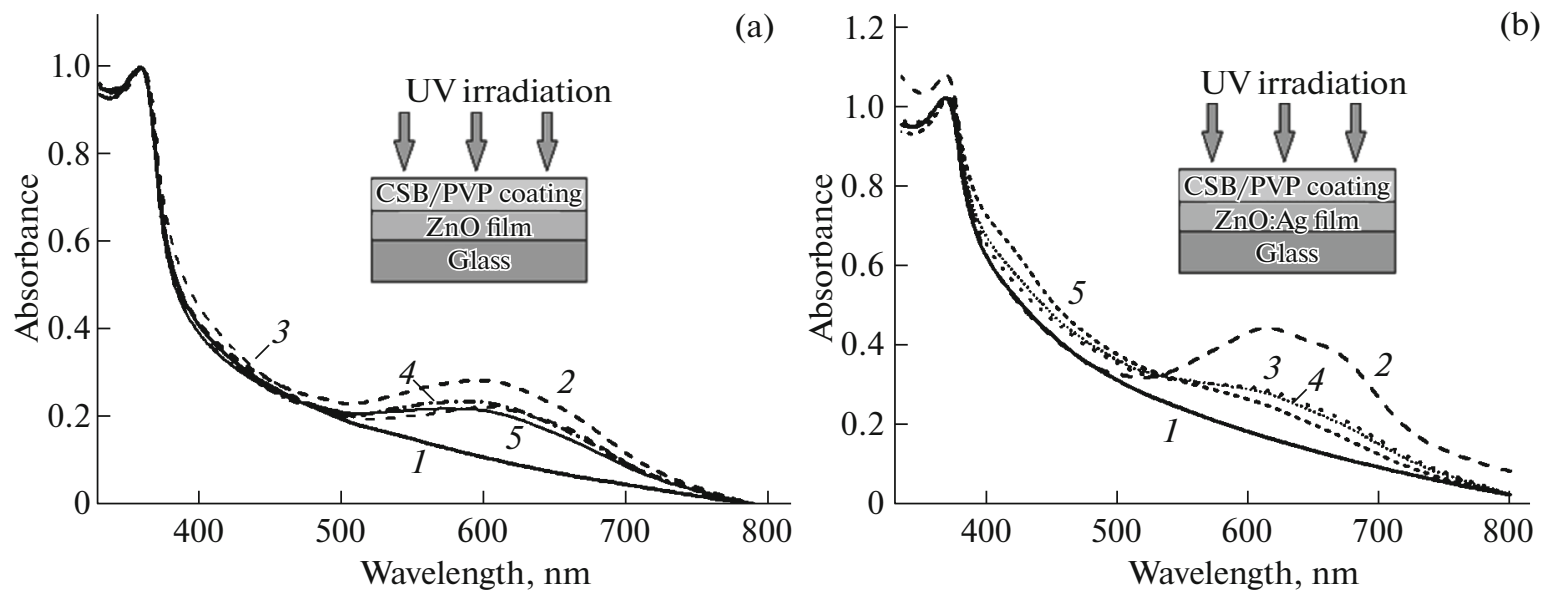

Fig. 4. Changes in the absorption spectra of samples with a CSB/PVP-composite coating deposited on (a) $\mathrm{ZnO}$ and (b) $\mathrm{ZnO}: \mathrm{Ag}$ oxide films on a glass surface. The $\mathrm{ZnO}$ :Ag film contains $86.3 \mathrm{wt} \%$ of $\mathrm{ZnO}$ and $13.7 \mathrm{wt} \% \mathrm{of} \mathrm{Ag}_{2} \mathrm{O}$. The structure of the samples is shown in the insets. The spectra correspond to the samples with (1) initial oxide coatings and (2-5) oxide films coated by CSB/PVP composite layers (2) before irradiation and after irradiation for (3) 10, (4) 20, and (5) 30 min. 
faces of $\mathrm{ZnO}$ and $\mathrm{ZnO}$ :Ag coatings occurs at approximately identical rates.

The spectra of samples with oxide coatings exhibit an exciton-absorption band typical for $\mathrm{ZnO}$ in the $\mathrm{UV}$ region with $\lambda_{\max }=370 \mathrm{~nm}$ [26]. It is known [16] that $\mathrm{ZnO}$ nanoparticles under the action of $\mathrm{UV}$ radiation at $\lambda \sim 365 \mathrm{~nm}$ produce various chemically active oxygen compounds (peroxide and hydroxyl radicals and singlet oxygen), which efficiently decompose organic compounds in contact with zinc oxide. Taking into account the width of the mercury-lamp spectrum in the UV region, we can suggest that these processes affect the diazo-dye decomposition in the films deposited on the surface of oxide coatings.

\section{CONCLUSIONS}

Our experiments showed that zinc and silver oxides strongly affect the CSB diazo-dye photolysis. The presence of zinc and silver nitrates in the aqueous solutions of this dye considerably increases the rate of the dye photolysis under UV irradiation. The $\mathrm{ZnO}$ and $\mathrm{ZnO}: \mathrm{Ag}$ films and composite coatings containing zinc and silver nitrates also noticeably affect the CSB photolysis.

\section{ACKNOWLEDGMENTS}

We are grateful to A.A. Goryunov (Service Center of St. Petersburg State Technological Institute (Technical University)) for performing electron-microscope investigations. The results are obtained using the equipment of the Engineering Center of St. Petersburg State Technological Institute (Technical University) within the framework of project no. 11.5884.2017/ITR. This work was supported by the Ministry of Education and Science of the Russian Federation, project no. 16.1651.2017/4.6.

\section{REFERENCES}

1. V. M. Kiselev, S. K. Evstropiev, and A. M. Starodubtsev, Opt. Spectrosc 123, 809 (2017).

2. C. Karunakaran, V. Rajeswari, and P. Gomathisankar, Solid State Sci. 13, 923 (2011).

3. Zulkarnain Zainal, Lee Kong Hui, Mohd Zobir Hussein, Yun Hin Taufiq-Yap, Abdul Halim Abdullah, and Irmati Ramli, J. Hazard. Mater. B 125, 113 (2005).

4. N. A. Volkova, S. K. Evstrop'ev, O. V. Istomina, and E. V. Kolobkova, Opt. Spectrosc. (2018, in press).

5. P. Basnet, G. K. Larsen, R. P. Jadeja, Y.-C. Hung, and Y. Zhao, ACS Appl. Mat. Interfaces 5, 2085 (2013).
6. S. K. Evstropiev, A. V. Karavaeva, K. V. Dukelskii, V. M. Kiselev, K. S. Evstropyev, N. V. Nikonorov, and E. V. Kolobkova, Ceram. Int. 43, 14504 (2017).

7. S. Guldin, P. Kohn, M. Stefik, J. Song, G. Divitini, F. Ecarla, C. Ducati, U. Wiesner, and U. Steiner, Nano Lett. 13, 5329 (2013).

8. V. M. Volynkin, S. K. Evstropiev, A. V. Karavaeva, K. V. Dukelskii, V. M. Kiselev, M. V. Bykov, and K. S. Evstropyev, J. Opt. Technol. 84, 477 (2017).

9. C. Minero, S. Chiron, G. Falletti, V. Maurino, E. Pelizzetti, R. Ajassa, M. E. Carlotti, and D. Vione, Aquatic Sci. 69, 71 (2007).

10. D. Chatterjee and S. Dasgupta, J. Photochem. Photobiol. C 6, 186 (2005).

11. Z. M. El-Bahy and A. A. Ismail, J. Hazard. Mater. 166, 138 (2009).

12. D. E. Zavastin, S. Gherman, and I. Cretescu, Rev. Chim. 63, 1075 (2012).

13. V. Jaškova, L. Hochmannova, and J. Vytřasová, Int. J. Photoenergy 2013, 795060 (2013). doi 10.1155/2013/795060

14. W. S. Chiu, P. S. Khiew, M. Cloke, D. Isa, T. K. Tan, S. Radiman, R. Abd-Shukor, M. A. Abd. Hamid, N. M. Huang, H. N. Lim, and C. H. Chia, Chem. Eng. J 158, 345 (2010).

15. J. H. Sun, S. Y. Dong, Y. K. Wang, and S. P. Sun, J. Hazard. Mater. 172, 1520 (2009).

16. Li Yang, Zhang Wen, Niu Junfeng, and Chen Yongsheng, ACS Nano 6, 5164 (2012).

17. R. M. Mohamed, I. A. Mkhalid, and S. A. Al-Thabaiti, and Mohamed Mokhtar, J. Nanosci. Nanotechnol. 13, 4975 (2013).

18. I. Othman, M. Tabet, and A. Farag, J. Int. Environ. Appl. Sci. 7, 661 (2012).

19. L. C. Abbott, S. N. Batchelor, and J. Oakes, J. Phys. Chem. B 108, 13786 (2004).

20. S. K. Evstropiev, K. V. Dukelskii, I. M. Kislyakov, K. S. Evstropyev, and Yu. A. Gatchin, Polym. Adv. Technol. 27, 1258 (2016).

21. K. V. Dukel'skii and S. K. Evstrop'ev, J. Opt. Technol. 78, 202 (2011).

22. V. N. Serova and E. N. Noskova, Vestn. Kazan. Tekhnol. Univ. 19 (15), 61 (2016).

23. The Chemistry of Synthetic Dyes, Ed. by K. Venkataram (Academic, New York, London, 1974), Vol. 3, p. 131.

24. P. Warneck and C. Wurzinger, J. Phys. Chem. 52, 6278 (1988).

25. P. A. Obraztsov, A. V. Nashchekin, N. V. Nikonorov, A. I. Sidorov, A. V. Panfilova, and P. N. Brunkov, Phys. Solid State 55, 1272 (2013).

26. Lin Guo, Shihe Yang, Chulei Yang, Ping Yu, Jiannong Wang, Weikun Ge, and G. K. L. Wong, Appl. Phys. Lett. 76, 2901 (2000).

Translated by M. Basieva 